\title{
Estimated effects of white rice consumption and rice variety selection on incidence of type 2 diabetes in Cambodia
}

\author{
Seila Sar ${ }^{1}$ and Geoffrey C Marks ${ }^{2, *}$
}

${ }^{1}$ The University of Queensland, Centre for Nutrition \& Food Sciences, Queensland Alliance for Agricultural \& Food Innovations, Brisbane, Queensland, Australia: ${ }^{2}$ The University of Queensland, School of Public Health, Herston, QLD 4006, Australia

Submitted 13 January 2014: Final revision received 27 August 2014: Accepted 9 December 2014: First published online 23 January 2015

\begin{abstract}
Objective: Rice consumption patterns are considered an important risk factor for diabetes in many countries. The present study aimed to model the impact of a shift in consumption of white rice from current to appropriately reduced levels and a shift in rice variety from one with a high glycaemic index to one with a low glycaemic index, on the burden of type 2 diabetes in Cambodia.

Design: Prevent Plus software was used to model the impact of selected changes to white rice consumption on the burden of type 2 diabetes. Data used for modelling included: demographic projections, relative risk estimates for white rice consumption and diabetes, diabetes incidence, rice type and quantities consumed. The 10-year projections were based on different scenarios of changes in risk factors.

Results: With no intervention, 10-year projections showed that total new diabetes cases will increase from 11315 (9.1 per 10000 person-years) for the year 2011 to 14852 new cases (12.4 per 10000 person-years) in 2020. However, this increase will be reduced by $27 \%$ (average across 10 years) with a change in rice variety from Phka Rumdual to IR66 and by $26 \%$ (average across 10 years) with a $25 \%$ reduction in quantity from current consumption levels.

Conclusions: Changing rice consumption patterns has potential for an important impact on diabetes risk, with a change of rice variety having a similar impact on the burden of diabetes in communities consuming rice with a high glycaemic index as a $25 \%$ reduction in the quantity of rice consumed. Similar effects are likely for other countries with rice as a staple food, diversity in rice varieties and high incidence of diabetes.
\end{abstract}

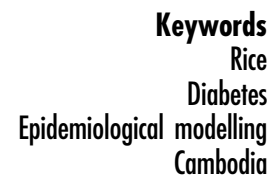

The glycaemic index (GI) of white rice ranges from 64 (SD 9) to 93 (SD 11) using an in vivo method ${ }^{(1)}$. The associations between dietary GI and glycaemic load (GL) and the risk of developing type 2 diabetes have been examined in several large-scale human observational studies. A positive association between dietary GL and risk of diabetes was supported by a recent meta-analysis that included twentyfour prospective cohort studies ${ }^{(2)}$. Significant positive associations have most consistently been reported in Asian populations (Chinese and Japanese) although the association was not significant in Japanese $\operatorname{men}^{(3,4)}$; however, mixed results were reported from cohort studies in Western populations where the levels of rice consumed were much lower than those in Asian populations ${ }^{(5,6)}$. The specific relationship between white rice consumption and risk of developing diabetes was supported by a meta-analysis of seven prospective cohort studies where the association was significant in Asian but not in Western populations ${ }^{(7)}$. This might be explained by a greater glycaemic response to rice in regular rice-eating populations (Asian) than seldom rice-eating Western populations ${ }^{(8)}$.

Rice is a staple food in Cambodia. It contributes at least $65 \%$ of the energy intake in the diet of most Cambodians ${ }^{(9)}$ who consume on average $462 \mathrm{~g} /$ person per d (uncooked weight ${ }^{(10)}$. A nationwide cross-sectional survey conducted in 2010 reported an overall prevalence of diabetes of $2.9 \%$, with it 2.4 times higher in urban $(5.6 \%)$ than in rural $(2.3 \%)$ areas $^{(11)}$; this prevalence is projected to increase to $5.6 \%$ by $2030^{(12)}$. Our previous study reported the considerable diversity in rice varieties grown and consumed in Cambodia ${ }^{(10)}$.

Given the impact of level of rice consumption on risk of diabetes, important GI differences across varieties of rice and the rapidly increasing impact of type 2 diabetes on 
health in Cambodia, the present study aimed to estimate the effects of selected changes to rice consumption patterns on the burden of diabetes for Cambodia: (i) a reduction in the consumption of white rice from current levels to appropriately reduced levels; and (ii) a shift from consumption of high-GI to low-GI rice varieties.

\section{Methods}

The Potential Impact Fraction (PIF) of these changes were estimated using Prevent Plus version $3 \cdot 0^{(13)}$. This software uses a combination of demographic and epidemiological models to estimate the effects of risk factor change scenarios on health outcomes in terms of the number of new cases and incidence rate ${ }^{(14)}$. Three main types of data are required to run the model: (i) demographic (baseline population sizes by age and sex); (ii) risk-factor-related data; and (iii) disease incidence.

\section{Current population and population projection of the study}

The latest census (2008) $)^{(15)}$ reported by the National Institute of Statistics of Cambodia was used as a baseline population for 2010 when the diabetes prevalence survey was conducted. The total population sizes for each year, from 2011 to 2020, were generated by Prevent Plus from this baseline taking into account the age- and sex-specific mortality rate from WHO (2011) ${ }^{(16)}$ and the birth rate from the 2010 Cambodia Demographic and Health Survey (CDHS) ${ }^{(17)}$. The modelling was restricted to the population aged 25-64 years to align with the available age-specific diabetes prevalence data. It considered the different rice consumption scenarios over a 10 -year projection between 2011 and 2020.

\section{Sources of data on prevalence of diabetes mellitus}

Data on the prevalence of diabetes were obtained from a nationwide cross-sectional survey carried out with a total of 5433 participants aged 25-64 years (96.3\% response rate), using the WHO STEPwise chronic disease risk factor surveillance methodology ${ }^{(11)}$. The age- and genderspecific prevalence estimates presented in Table 1 were extracted to calculate baseline incidence of diabetes using
DisMod $\mathrm{II}^{(18)}$. This takes into account: current diabetes prevalence, remission, and age- and sex-specific relative risk (RR) of dying in individuals with diabetes compared with individuals without diabetes from the study on global burden of mortality attributable to diabetes ${ }^{(19)}$.

\section{Sources of data on distribution of rice consumption patterns}

Information on rice consumption in Cambodia was derived from our cross-sectional study on household rice choice and consumption behaviour carried out in $2010^{(10)}$. This survey had a total of 250 respondents aged 18-75 years, selected using stratified multistage sampling to obtain a representative sample of rural and urban households in the five agro-climatic zones across the country. Only respondents aged 25-64 years were used here, leaving a total of 224 respondents. The original data were used to generate quantity of rice consumed for calculation of the PIF. Uncooked rice quantities were converted to cooked rice by multiplying with a factor of $2 \cdot 5$ following the approach used elsewhere ${ }^{(7)}$. Age- and gender-specific rice consumption estimates are presented in Table 2 .

The quality of the studies used for estimating diabetes prevalence and rice consumption patterns was assessed as at low risk of bias using a tool for assessing risk of bias in prevalence studies ${ }^{(20)}$.

\section{Sources of data on relative risk}

A systematic literature search identified all articles reporting the relationship of GI, GL or white rice intake and the risk of developing type 2 diabetes (up to the end of January 2013). Because all the studies identified were included in recently published meta-analyses, we decided to use the estimate of pooled RR from these studies. The meta-analyses by Livesey et al. ${ }^{(2)}$ and Hu et al. ${ }^{(7)}$ reported a convincing causal association between dietary GL and white rice consumption, respectively, and the risk of diabetes. The quality of each meta-analysis was assessed using AMSTAR, a measurement tool to assess the methodological quality of systematic reviews ${ }^{(21)}$. The study quality for both studies was highly reliable with an AMSTAR score of 10 (out of a maximum of 11). The estimated RR data from Livesey et al. were used for the main

Table 1 Prevalence of diabetes in Cambodia*

\begin{tabular}{|c|c|c|c|c|c|c|c|}
\hline \multirow[b]{2}{*}{ Age range (years) } & \multirow[b]{2}{*}{$n$} & \multicolumn{2}{|c|}{ Male } & \multicolumn{2}{|c|}{ Female } & \multicolumn{2}{|c|}{ Total } \\
\hline & & $\%$ & $95 \% \mathrm{Cl}$ & $\%$ & $95 \% \mathrm{Cl}$ & $\%$ & $95 \% \mathrm{Cl}$ \\
\hline $25-34$ & 1332 & 1.3 & $0.1,2.5$ & 0.9 & $0.1,1.7$ & $1 \cdot 1$ & $0.4,1.8$ \\
\hline $35-44$ & 1430 & 2.2 & $0.9,3.5$ & $2 \cdot 3$ & $1 \cdot 2,3.3$ & $2 \cdot 2$ & $1.4,3.0$ \\
\hline $45-54$ & 1385 & 4.0 & $2 \cdot 1,5 \cdot 8$ & 5.5 & $3.5,7.5$ & 4.8 & $3 \cdot 5,6 \cdot 1$ \\
\hline $55-64$ & 976 & $4 \cdot 2$ & $2 \cdot 0,6 \cdot 3$ & $7 \cdot 7$ & $5 \cdot 1,1 \cdot 4$ & $6 \cdot 0$ & $4 \cdot 4,7 \cdot 7$ \\
\hline Total & 5123 & 2.5 & $1 \cdot 7,3 \cdot 3$ & $3 \cdot 3$ & $2 \cdot 5,4.0$ & 2.9 & $2 \cdot 3,3 \cdot 4$ \\
\hline
\end{tabular}

*Data on prevalence of diabetes were taken from a nationwide cross-sectional survey on the prevalence of non-communicable disease risk factors in Cambodia reported by Oum et al. $(2010)^{(11)}$. 
Table 2 Daily intake of cooked white rice consumed by Cambodians (g/person)*

\begin{tabular}{|c|c|c|c|c|c|c|c|}
\hline \multirow[b]{2}{*}{ Variable } & \multirow[b]{2}{*}{$n$} & \multicolumn{2}{|c|}{ Male } & \multicolumn{2}{|c|}{ Female } & \multicolumn{2}{|c|}{ Total } \\
\hline & & Mean & $95 \% \mathrm{Cl}$ & Mean & $95 \% \mathrm{Cl}$ & Mean & $95 \% \mathrm{Cl}$ \\
\hline \multicolumn{8}{|c|}{ Age range (years) } \\
\hline $25-34$ & 59 & 1150 & 535,1765 & 1149 & 957,1340 & 1149 & 971,1327 \\
\hline $35-44$ & 69 & 1323 & 665,1981 & 1167 & 1056,1277 & 1185 & 1069,1300 \\
\hline $45-54$ & 64 & 1540 & 1185,1894 & 1061 & 916,1207 & 1188 & 1042,1335 \\
\hline $55-64$ & 32 & 1281 & 638,1923 & 926 & 778,1075 & 1015 & 835,1195 \\
\hline \multicolumn{8}{|l|}{ Quartile } \\
\hline 1 & 56 & 559 & 439,679 & 563 & 533,593 & 563 & 534,591 \\
\hline 2 & 56 & 920 & 854,986 & 901 & 878,924 & 904 & 882,925 \\
\hline 3 & 56 & 1197 & 1129,1265 & 1191 & 1167,1215 & 1192 & 1170,1214 \\
\hline 4 & 56 & 2085 & 1782, 2387 & 1867 & 1722,2013 & 1923 & 1793,2054 \\
\hline Total & 224 & 1388 & 1160,1616 & 1104 & 1027,1181 & $1152 \dagger$ & 1071,1227 \\
\hline
\end{tabular}

${ }^{*}$ Rice consumption data were based on a cross-sectional survey of rice choice and consumption behaviour of Cambodians reported by Sar et al. (2012) ${ }^{(10)}$. The data were re-analysed and reported for the respondents aged 25-64 years only.

tRaw rice intake was converted to cooked rice intake by multiplication with a factor of 2.5 .

modelling in our study since they took into account both the quantity (consumption level) and quality (GI) of the diet. We used the RR estimate from Hu et al. to check the sensitivity of the results to RR selection.

\section{Data analysis}

To determine the burden of diabetes attributable to white rice consumption, Prevent Plus uses the PIF to assess proportional changes in incidence of diabetes for different scenarios. We estimated the changes that would occur if the current consumption distribution was shifted to a feasible lower level and if a high-GI rice variety was consumed instead of a low-GI rice variety.

PIF calculation involving categorical $v$. continuous variables is considered in detail by Barendregt and Veerman ${ }^{(22)}$. The continuous scenario uses the concept of theoretical minimum-risk exposure distribution (TMRED) ${ }^{(23,24)}$, the alternative distribution of exposure expected to produce the lowest possible disease risk associated with the exposure ${ }^{(25)}$. It needs to be possibly and feasibly achievable ${ }^{(25)}$. In practice this is generally based on evidence from epidemiological studies using the levels of exposure observed in populations that are considered low-risk regardless of age or sex. In the absence of other evidence indicating low-risk yet feasible rice intakes in the Cambodian or comparable populations, the TMRED used in the present study was determined as the upper end of the first quartile of the rice consumption distribution. We estimated the reduction in diabetes incidence that would occur if the population changed from the current average level of rice consumption to an intervention level determined as half way to the TMRED. The categorical scenario involved shifting from consuming a high-GI rice variety to a low-GI rice variety. PIF was calculated on the basis of age- and gender-specific exposure data and RR of disease incidence at the corresponding levels of exposure.

The two commonly consumed rice varieties selected were Phka Rumduol and IR66, with high GI (88) and low GI (54), respectively (CSIRO analyses, personal communication).
The in vitro method used to obtain GI values for the two samples was conducted following a method reported elsewhere $^{(26)}$ with slight modification of the cooking and grinding methods.

\section{Assumptions used in the study}

General assumptions

Modelling was conducted using the following assumptions. Rice consumption levels as reported by Sar et al. ${ }^{(10)}$ were assumed to be representative of the Cambodian adult population. Diabetes is a lifelong disease (Remission $=0$ ). The effect of white rice consumption on risk of diabetes may have a specific latency time. However, since there is very limited information on the latency of diabetes in the literature we assumed no latency time for diabetes (LAT $=0$ and $\mathrm{LAG}=0$ ). Calculation of the projected population assumed no migration.

\section{Assumptions for modelling the effects of rice variety}

We first assumed that the entire Cambodian population consumed only the high-GI rice variety (Phka Rumduol) with the current consumption level of $1152 \mathrm{~g} / \mathrm{d}$ for the baseline year 2010. The scenario assumed that the whole population changed to consume the low-GI rice variety (IR66) from 2011 until 2020. This estimates the maximum effect of a change in rice variety. Second, we assumed that rice makes the main contribution to daily total dietary GL while other foods have minimal contribution. GL was calculated following the method reported elsewhere ${ }^{(27)}$. The absolute GL values per current daily rice consumption level used in the model are 222 and 378 for IR66 and Phka Rumduol varieties, respectively. Pooled RR of the association of dietary GL and the risk of diabetes was $1.45 / 100 \mathrm{~g}$ increment in GL in an $8368 \mathrm{~kJ}$ (2000 kcal) intake. This linear dose-response relationship was assumed for the whole range of GL for the present study. The absolute GL was used in the main analysis, with GL per $8368 \mathrm{~kJ}$ (2000 kcal) diet used to check the sensitivity of the results. Finally, RR was assumed to be equal across genders. 
Assumptions for modelling the effects of rice quantity

The average quantity of rice consumed by the whole population $(1152 \mathrm{~g} / \mathrm{d})$ calculated from Sar et al. ${ }^{(10)}$ was assumed as the current rice consumption level and TMRED as the upper end of the first quartile of consumption $(563 \mathrm{~g} / \mathrm{d})$. The intervention level $(858 \mathrm{~g} / \mathrm{d})$ was determined as half way from the current consumption level to the TMRED. Therefore, the intervention involved a reduction of $25 \%$ in quantity of rice consumed ( $294 \mathrm{~g}$ on average per $d$ ). All rice varieties were assumed in this scenario to have the same effects on diabetes risk. Quantity of rice consumed was converted to absolute GL intake, using the GI value (71) as the average of the low and high GL values mentioned above. The estimated RR of Livesey et al. ${ }^{(2)}$ was used for the main analysis, just as in the modelling of the effects of changing rice variety. However, the estimates of $\mathrm{Hu}$ et al. ${ }^{(7)}$, with $\mathrm{RR}=1 \cdot 11$ for a $158 \mathrm{~g} / \mathrm{d}$ increment of white rice intake, was used as a complementary analysis to check the sensitivity of the results. This linear dose-response relationship was assumed to be stable for the whole range of rice consumption distribution in Cambodia. The RR used in this analysis was not different across genders.

\section{Results}

\section{Effects of the change of rice variety}

The estimated total new diabetes cases by year for the 10-year projection, 2011-2020, corresponding to different rice varieties consumed are shown in Fig. 1(a). This number increases from 11315 in 2011 to 14852 new cases for 2020 with continued consumption of Phka Rumduol (an increase in incidence from 9.1 to 12.4 per 10000 person-years). However, this would be reduced by $26.7 \%$ (from 11315 to 8297 new cases; or from $9 \cdot 1$ to $6 \cdot 7$ per 10000 person-years) for 2011 and by $27 \cdot 1 \%$ (from 14852 to 10821 new cases; or from $12 \cdot 4$ to $9 \cdot 1$ per 10000 person-years) for 2020 if the population changed to consume IR66 instead. The total number of new cases associated with consuming both rice varieties over these 10 years is estimated to be higher in women than men. The same patterns are seen for incidence rates (results not shown).

The proportional reduction of estimated new cases associated with a change of rice variety from Phka Rumduol to IR66 is presented in Table 3. The shift has equal effects across genders; however, this effect of changing rice variety is quite different for higher age groups. The reduction is higher (43\%) in the oldest age group (60-64 years) compared with all younger age groups (26\%).

\section{Effects of the reduction of rice quantity}

Figure 1(b) shows the distribution of the estimated total number of new diabetes cases by year for a 10 -year projection for both the current consumption level (1152 g/d)
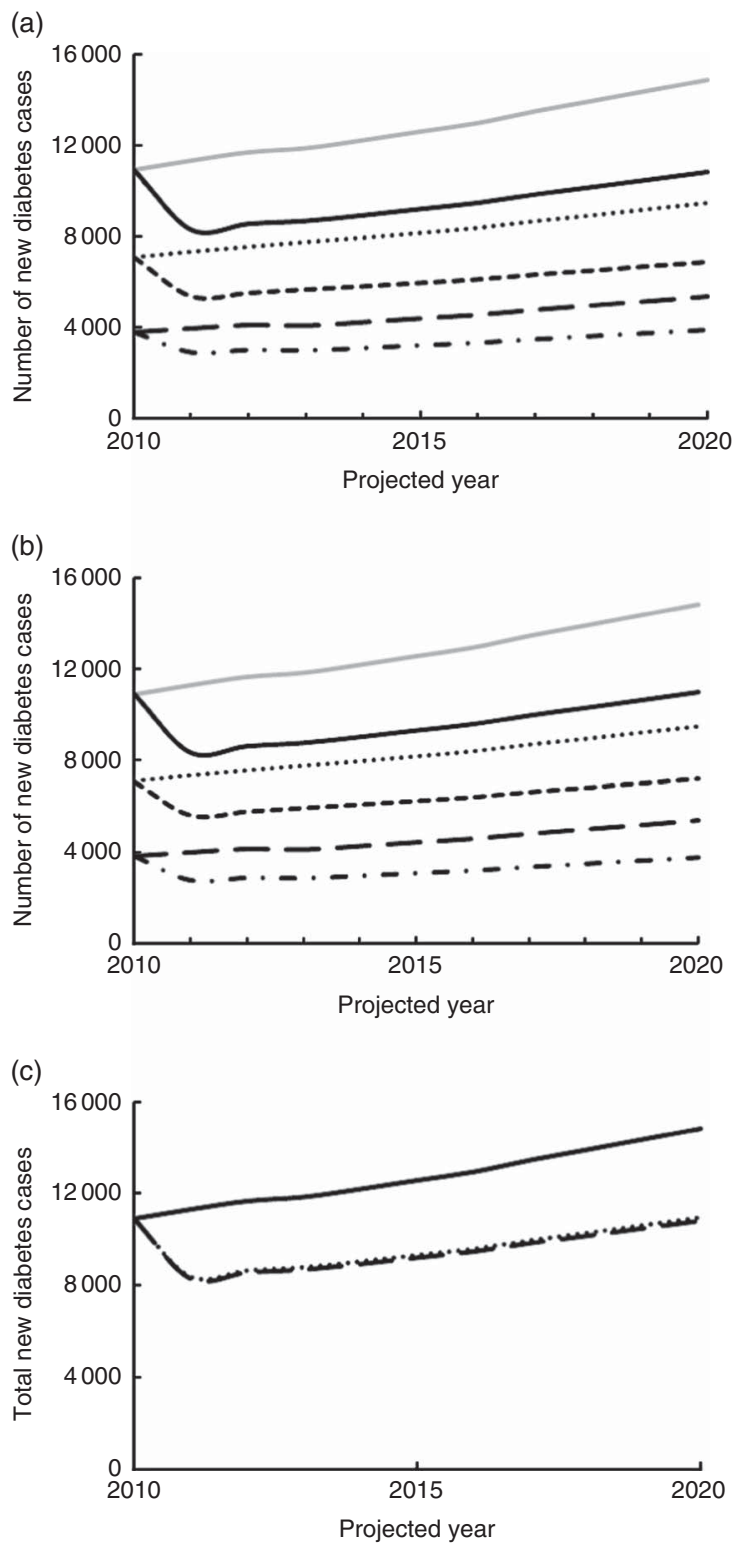

Fig. 1 Projected incidence of diabetes in Cambodia by year, 2010-2020, under different intervention scenarios: (a) incidence of diabetes by sex and year corresponding to changing from Phka Rumduol (PR) to IR66 rice variety (_ (total); ......., PR (women); -.-., IR66 (women); — -, PR (men); - - -, IR66 (men)); (b) incidence of diabetes by sex and year corresponding to a reduction from the current rice consumption level, $1152 \mathrm{~g} / \mathrm{d}$, to the intervention level, $858 \mathrm{~g} / \mathrm{d}$ ( - , current level (total); —, intervention (total); ...... current level (women); -- ---, intervention (women); - - c current level (men); - - - intervention (men)); (c) comparison between the effects of a reduction in rice consumption level and changing rice variety on total incidence of diabetes ( - , current consumption;...... , reducing quantity; $\_-$, changing variety)

and the intervention consumption level $(858 \mathrm{~g} / \mathrm{d})$. Total new cases for each year are greater for the higher consumption level. The estimated new diabetes cases will be reduced by $26 \%$ (from 11315 to 8369 new cases; or from $9 \cdot 1$ to $6 \cdot 7$ per 10000 person-years) for 2011 and also by $26 \%$ (from 14852 to 10986 new cases; or from $12 \cdot 4$ to $9 \cdot 2$ 
Table 3 PIF (\%) for diabetes attributable to making selected changes to daily white rice consumption patterns in Cambodia

\begin{tabular}{lccccc}
\hline & \multicolumn{2}{c}{ Reducing rice quantity* } & & \multicolumn{2}{c}{ Changing rice variety $\dagger$} \\
\cline { 2 - 3 } \cline { 5 - 6 } Age range (years) & Men & Women & & Men & Women \\
\hline $25-54$ & 27 & 20 & 26 & 26 \\
$55-59$ & 20 & 15 & & 26 & 26 \\
$60-64$ & 30 & 22 & & 43 & 43 \\
\hline
\end{tabular}

PIF, Potential Impact Fraction; Gl, glycaemic index. ${ }^{*}$ Reducing from $1152 \mathrm{~g}$ to $858 \mathrm{~g}$ on average per $\mathrm{d}$. †Changing from Phka Rumduol (high GI) to IR66 (low GI) rice variety.

per 10000 person-years) for 2020 if the population consumption reduces to $858 \mathrm{~g}$ on average per $\mathrm{d}$.

Based on the PIF analysis, the effect of reducing quantity of rice consumption on the incidence of diabetes seems to be more effective in men than women (Table 3 ). In men, the reduction increases from $20 \%$ in the younger age group (55-59 years) to $30 \%$ in the oldest age group (60-64 years) while in women only a $15 \%$ reduction is seen in the younger age group and $22 \%$ for the oldest age group. The different effects among the age groups shown here are attributable to differences in quantities of rice consumption across the age groups.

Figure 1(c) provides a comparison of the effects of changing rice variety and reducing rice quantity consumed on the numbers of new cases over time. The size of the effects for the two interventions are very similar, both showing a marked reduction from current levels of diabetes

\section{Discussion}

The present study is the first assessment of the effects of white rice consumption on the burden of type 2 diabetes in Cambodia. From the PIF analysis, the results indicate that changing rice varieties from Phka Rumduol (high GI) to IR66 (low GI) could lead to a reduction in the incidence of diabetes from $26 \%$ to $43 \%$ for adults aged $25-64$ years; the impact was estimated to be higher in the oldest age groups (60-64 years old) which could be due to the higher prevalence of diabetes in this age group compared with younger age groups. The equal proportional reduction in the estimated new diabetes cases across genders caused by change in rice variety may be attributed to use of the same assumptions concerning the change in rice variety and equal RR for men and women. In addition, the change in the estimated number of new diabetes cases attributable to an average reduction of $294 \mathrm{~g}$ of rice per d calculated using the PIF formula was projected to be $15-30 \%$. The effect of the intervention was more effective in men than women and was different across age groups. This can be attributed to the higher quantity of rice consumed by men than women and the difference in quantity of rice consumed across age groups, respectively. The larger estimated number of new diabetes cases by year in women for each scenario appears to be mainly due to the higher baseline diabetes incidence in women than men. The increase in number of new cases by year observed in each scenario can be attributed to the overall population growth of Cambodia (annual growth rate of $1.54 \%$ ), the increased number of new cases from the younger age groups moving into the older age ranges and the small effect of the oldest age group on overall mortality because of its small proportion in the whole population.

The results of the projection from the present study also suggest that the average annual new diabetes cases (12740 new cases per year, average across 10 years) is higher than the previous projection ( 9000 new cases per year, average across 20 years) using the same baseline prevalence of diabetes in Cambodia ${ }^{(28)}$; however, the authors from the previous study had recognized the underestimate of the results due to the conservative approach used.

The validity of these results clearly depends on the appropriateness of the estimates used in the modelling. The survey by Sar et al. ${ }^{(10)}$ is the most recent and detailed data on quantity of rice consumed by the Cambodian population, based on a sample across all five agro-climatic zones of the country. Recent FAO estimates of the annual total quantity of rice consumed per capita were quite similar to the results used here $(168 \mathrm{~kg}$ in 2010) with FAO (FAOSTAT database) reporting $160 \mathrm{~kg}$ in 2009. Therefore, this estimate appears to have reasonable validity.

An important feature of rice consumption patterns in Cambodia is the diversity in varieties consumed. Our previous study reported thirty-four and thirty-six rice varieties being grown and consumed by 250 households, respectively, and a focus on the ten most popular rice varieties would include only two-thirds of respondents ${ }^{(10)}$. Rice growing and consumption in Cambodia also vary across seasons $^{(10)}$ and the digestibility of Cambodian rice varies across varieties ${ }^{(29)}$. However, there are frequently dominant rice varieties grown and consumed by particular communities. Thus our selection of an average of the GI to reflect current consumption provides an appropriate estimate of aggregate risk and benefit from change, with actual risks for individual Cambodian communities expected to vary according to the GI of the dominant varieties they consume.

The GI values of the two rice varieties reported in the present study were predicted GI measured by an in vitro method. The validation of this in vitro method was done against the in vivo measurement of GI on identical samples of more than thirty different foods comprising a wide range of GI values, which revealed a strong relationship between 'predicted' and 'true' GI values $\left(r^{2}=0 \cdot 81\right)^{(30)}$. The correlation was slightly stronger $\left(r^{2}=0.85\right)$ for the rice samples ${ }^{(26)}$.

In the present study we used the diabetes prevalence data from Oum et al. ${ }^{(11)}$, where diabetes was defined as an individual who has a fasting glucose $\geq 6.1 \mathrm{mmol} / \mathrm{l}$ or 
previously diagnosed with diabetes and currently on diabetes treatment. This is below the cut-off value $(\geq 7 \cdot 0$ $\mathrm{mmol} / \mathrm{l})$ for the diabetes definition of the $\mathrm{WHO}^{(31)}$ and American Diabetes Association ${ }^{(32)}$. Therefore, this would overestimate the prevalence of diabetes in the population relative to these criteria (by including people with fasting glucose of $6 \cdot 1-6.9 \mathrm{mmol} / \mathrm{l})$, but is consistent with the recommendations for Asian populations suggested by Ko based on research in Hong Kong ${ }^{(33)}$. People with fasting glucose of $6 \cdot 1-6.9 \mathrm{mmol} / \mathrm{l}$ were defined by the WHO and American Diabetes Association as an intermediate group of impaired fasting glycaemia who have a very high tendency to develop diabetes in the future. We found no basis for applying a different RR to these two categories.

In addition, the use of these prevalence data to estimate the baseline incidence of diabetes is potentially sensitive to the assumptions on mortality and remission rates. The literature was reviewed to identify feasible ranges for the mortality and diabetes remission rates for the Cambodian population. The only other source of mortality data available was reported in the CDHS (2010) ${ }^{(17)}$ and so this was used as an alternative mortality estimate for the analysis. Given that specialist diabetes treatment is not commonly available in Cambodia, we set the upper level for remission rate at $2 \%$, based on the level of remission reported for the education control arm in a large-scale randomized controlled trial of an intensive lifestyle intervention for treatment of diabetes ${ }^{(34)}$. Sensitivity analyses were undertaken to assess the effect of variation in these assumptions, both separately and together, on the main results of the study. It was found that the slight change in mortality rates resulted in little change in the estimated total new diabetes cases for both rice quantity and rice variety interventions ( $1 \%$ higher when using mortality from WHO compared with mortality from CDHS; results not shown). The effect was larger for remission, with a $2 \%$ change in diabetes remission showing $26 \%$ higher incidence, while a combined change of both mortality rate from CDHS with $2 \%$ diabetes remission showed a $25 \%$ increase in estimated total new diabetes cases for both rice variety and rice quantity interventions as compared with the initial use of mortality rate from WHO with $0 \%$ diabetes remission. However, the proportional reduction of estimated new cases for both rice variety and rice quantity interventions was similar to the initial findings (results not shown), with the overall findings and conclusions from the modelling unchanged.

The RR of 1.45 for the increment of $100 \mathrm{~g}$ of GL per $8368 \mathrm{~kJ}$ (2000 kcal) from Livesey et $a l^{(2)}$ was energyadjusted in their analysis and de-attenuated for dietary instrument correlation for carbohydrate, and adjusted for sex, duration of follow-up and ethnicity in addition to the adjustment for confounders in the individual original studies included in the analysis. The decision to use the RR estimates from Livesey et al.'s study instead of $\mathrm{Hu}$ et al. ${ }^{(7)}$ was made on the basis that the dose-response analysis of the relationship between exposure and outcome was done by taking into account the quality (GI) of the food and adjusted for ethnicity, while these were not taken into account in the meta-analysis by Hu et al. Further, we would have needed to extrapolate beyond the range of rice intakes reported by $\mathrm{Hu}$ et al. To assess the impact of this decision, we repeated the final stage of the analysis using the RR from $\mathrm{Hu}$ et al. The key results were very similar (estimated incidence an average of $5 \%$ lower across 10 years of projection; results not shown) and our conclusions would not have changed through using these estimates.

The measure of RR based on an increment of $100 \mathrm{~g}$ of GL per $8368 \mathrm{~kJ}$ (2000 kcal) was used by Livesey et al. ${ }^{(2)}$ to adjust for differences across studies in overall energy intakes. One outcome of this is that the effects on diabetes risk are framed as GL relative to total energy, rather than as absolute GL. However, there does not appear to be a consensus in the literature around whether absolute or relative GL is more important for reflecting the risk for diabetes. We converted rice into absolute GL, not GL per $8368 \mathrm{~kJ}(2000 \mathrm{kcal})$, and used this for the modelling. The absolute GL values we used are in the same range as in the original studies included in the meta-analysis of Livesey et al. and the combination of the original studies and the meta-analysis shows that both absolute and relative GI values are associated with risk of diabetes. Based on food balance sheet estimates, FAO has reported that the average daily food energy intake of Cambodians was $9966 \mathrm{~kJ}$ (2382 kcal) per capita in 2009. Using this, GL become a little higher when corrected to a per $8368 \mathrm{~kJ}$ (2000 kcal) standard. We decided to use the absolute GL for the modelling rather than make additional assumptions on the total energy intake of the diet and the contribution of rice to the total energy intake. However, to assess the sensitivity of our findings to this decision we compared the main results using absolute and relative GL. Using GL per $8368 \mathrm{~kJ}$ (2000 kcal) compared with absolute GL as the input for modelling showed a slightly higher number of total new diabetes cases ( $3 \%$, average across 10 years of projection) when people change from Phka Rumduol to IR66 rice variety (results not shown). Similar effects were found in the modelling for changes in rice quantity consumed ( $1 \%$ difference, average across 10 years of projection; results not shown). To the extent that we are making the same assumptions across each of those scenarios, we expect any effect of absolute $v$. relative GL on the results and the conclusions to be minimal.

Dietary consumption patterns are strongly associated with risk of developing a range of chronic diseases. Rice is the staple food in Cambodia and so any effect of rice variety and quantity on health is likely to be important at the population level. Cambodians consume rice at least two to three times daily. To completely take away the total burden of diabetes attributed to white rice consumption would require people to stop consuming rice, which is not a feasible scenario. The feasible options are to reduce the 
quantity and/or change the variety of rice consumed to minimize these effects on rice consumers. Our findings show that the projected incidence of diabetes will be reduced by $27 \%$ (average across 10 years) if people change from Phka Rumdual to IR66 variety and by $26 \%$ (average across 10 years) if they reduce the quantity of rice by $25 \%$ from the current consumption level. These findings suggest that changing rice variety would have similar effects on the burden of diabetes in high-GI rice communities in Cambodia as the reduction of the quantity of rice consumed.

In the reduction in rice quantity scenario, when $25 \%$ of rice is removed, food replacement needs to be considered. In Cambodia, there is a potential to increase the consumption of vegetables and fruits, as it was reported that Cambodians consumed on average 1 serving of fruits and $2 \cdot 1$ servings of vegetables daily ${ }^{(11)}$. The replacement food needs to be available, acceptable and affordable by the consumers and this requires further investigation. Therefore, replacing a high-GI with a lower-GI rice variety scenario could be a more appealing and probably a more realistic option since people do not need to find ways to substitute the rice with some other carbohydrate food sources. Changing from high- to low-GI rice varieties would not have any important implications for food production since IR66 has a higher yield and could be grown more often (both dry and wet seasons) as compared with Phka Rumduol, which can be grown only in the wet season.

While we did not model the combined effects explicitly, the combination of a reduction in quantity of rice together with selection of a low-GI rice variety for daily consumption is expected to result in a larger positive impact. Both contribute to total GL, the measure used in the metaanalysis by Livesey et al. ${ }^{(2)}$.

Cambodia is one of a several countries where rice is a staple food and there is a diversity of rice varieties consumed. The literature suggests that similar effects are likely to be found in other countries such as Sri Lanka, Bangladesh, Indonesia, Malaysia and India ${ }^{(35)}$ where there is a very high incidence of diabetes, rice is a staple food ${ }^{(36,37)}$ and a mixture of low- and high-GI rice varieties is commonly consumed ${ }^{(38-42)}$.

The results from the present study provide important information on the public health implications of rice consumption, which need to be considered for food production and consumption policies in Cambodia as well as other riceconsuming countries. These findings also potentially provide encouragement to scientists to develop rice varieties with better nutritional value, as a food-based strategy to mitigate the onset of type 2 diabetes and other related chronic diseases.

\section{Acknowledgements}

Acknowledgements: S.S. thanks The University of Queensland for his postgraduate scholarship. The authors thank
Associate Professor Jan J. Barendregt for technical advice on the use of Prevent Plus and DisMod II software tools. Financial support: This research received no specific grant from any funding agency in the public, commercial or notfor-profit sectors. Conflict of interest: None. Authorship: Both authors, S.S. and G.C.M., were involved in study design. S.S. was responsible for database development, data analysis and wrote the first draft of the manuscript. G.C.M. advised and made comments on the draft. Both authors contributed to the revision of the manuscript and approved the final version. Ethics of buman subject participation: Ethical approval was not required.

\section{References}

1. Brand-Miller JB, Pang E \& Bramall L (1992) Rice: a high or low glycemic index food? Am J Clin Nutr 56, 1034-1036.

2. Livesey G, Taylor R, Livesey H et al. (2013) Is there a doseresponse relation of dietary glycemic load to risk of type 2 diabetes? Meta-analysis of prospective cohort studies. Am J Clin Nutr 97, 584-596.

3. Nanri A, Mizoue T, Noda M et al. (2010) Rice intake and type 2 diabetes in Japanese men and women: the Japan Public Health Center-based Prospective Study. Am J Clin Nutr 92, 1468-1477.

4. Villegas R, Liu S, Gao YT et al. (2007) Prospective study of dietary carbohydrates, glycemic index, glycemic load, and incidence of type 2 diabetes mellitus in middle-aged Chinese women. Arch Intern Med 167, 2310-2316.

5. Hodge AM, English DR, O'Dea K et al. (2004) Glycemic index and dietary fiber and the risk of type 2 diabetes. Diabetes Care 27, 2701-2706.

6. Sun Q, Spiegelman D, van Dam RM et al. (2010) White rice, brown rice, and risk of type 2 diabetes in US men and women. Arch Intern Med 170, 961-969.

7. Hu EA, Pan A, Malik V et al. (2012) White rice consumption and risk of type 2 diabetes: meta-analysis and systematic review. BMJ 344, e1454.

8. Kataoka M, Venn B, Williams S et al. (2013) Glycaemic responses to glucose and rice in people of Chinese and European ethnicity. Diabetic Med 30, e101-e107.

9. Maltsoglou I, Dawe D \& Tasciotti L (2010) Household Level Impacts of Increasing Food Prices in Cambodia. Rome: FAO.

10. Sar S, Gilbert RG \& Marks GC (2012) Household rice choice and consumption behavior across agro-climatic zones of Cambodia. J Hunger Environ Nutr 7, 333-346.

11. Oum S, Prak PR, Khuon EM et al. (2010) Prevalence of NonCommunicable Disease Risk Factors in Cambodia: STEPS Survey Country Report, September 2010. Phnom Penh: University of Health Sciences and Ministry of Health.

12. Shaw J, Sicree R \& Zimmet P (2010) Global estimates of the prevalence of diabetes for 2010 and 2030. Diabetes Res Clin Pract 87, 4-14.

13. Soerjomataram I, De Vries E, Engholm G et al. (2010) Impact of a smoking and alcohol intervention programme on lung and breast cancer incidence in Denmark: an example of dynamic modelling with Prevent. Eur J Cancer 46, 2617-2624.

14. Veerman JL, Barendregt JJ, Mackenbach JP et al. (2006) Using epidemiological models to estimate the health effects of diet behaviour change: the example of tailored fruit and vegetable promotion. Public Health Nutr 9, 415-420.

15. National Institute of Statistics (2009) General Population Census of Cambodia 2008. Phnom Penh: Ministry of Planning. 
16. World Health Organization (2011) Global Health Observatory. http://apps.who.int/gho/athena/data/download.xsl?format= $\mathrm{xml} \& \operatorname{target}=\mathrm{GHO} /$ LIFE_0000000029\&profile $=$ excel\&filter $=$ COUNTRY:KHM;YEAR:2011;SEX:FMLE;SEX:MLE (accessed July 2013).

17. National Institute of Statistics, Directorate General for Health \& ICF Macro (2011) Cambodia Demographic and Health Survey 2010. Phnom Penh and Calverton, MD: Ministry of Planning and ICF Macro.

18. Barendregt JJ, Van Oortmarssen GJ, Vos T et al. (2003) A generic model for the assessment of disease epidemiology: the computational basis of DisMod II. Popul Health Metr $\mathbf{1}, 4$.

19. Roglic G, Unwin N, Bennett PH et al. (2005) The burden of mortality attributable to diabetes realistic estimates for the year 2000. Diabetes Care 28, 2130-2135.

20. Hoy D, Brooks P, Woolf A et al. (2012) Assessing risk of bias in prevalence studies: modification of an existing tool and evidence of interrater agreement. J Clin Epidemiol 65 , 934-939.

21. Shea BJ, Grimshaw JM, Wells GA et al. (2007) Development of AMSTAR: a measurement tool to assess the methodological quality of systematic reviews. BMC Med Res Methodol 7, 10.

22. Barendregt JJ \& Veerman JL (2010) Categorical versus continuous risk factors and the calculation of potential impact fractions. J Epidemiol Community Health 64, 209-212.

23. Ezzati M, Lopez AD, Rodgers A et al. (2004) Comparative Quantification of Health Risks. Global and Regional Burden of Disease Attributable to Selected Major Risk Factors. Geneva: WHO.

24. Micha R, Kalantarian S, Wirojratana P et al. (2012) Estimating the global and regional burden of suboptimal nutrition on chronic disease: methods and inputs to the analysis. Eur J Clin Nutr 66, 119-129.

25. Murray CJ, Ezzati M, Lopez AD et al. (2003) Comparative quantification of health risks: conceptual framework and methodological issues. Popul Health Metr 1, 1.

26. Fitzgerald M, Rahman S, Resurreccion A et al. (2011) Identification of a major genetic determinant of glycaemic index in rice. Rice $\mathbf{4}, 66-74$.

27. Salmeron J, Manson JAE, Stampfer MJ et al. (1997) Dietary fiber, glycemic load, and risk of non-insulin-dependent diabetes mellitus in women. JAMA 277, 472-477.
28. Whiting DR, Guariguata L, Weil C et al. (2011) IDF diabetes atlas: global estimates of the prevalence of diabetes for 2011 and 2030. Diabetes Res Clin Pract 94, 311-321.

29. Syahariza ZA, Sar S, Hasjim J et al. (2013) The importance of amylose and amylopectin fine structures for starch digestibility in cooked rice grains. Food Chem 136, 742-749.

30. Bird T (2011) Report on the Accuracy and Precision of the CSIRO Laboratory Method for Predicting Glycemic Index. Adelaide, SA: CSIRO.

31. World Health Organization (2006) Definition and Diagnosis of Diabetes Mellitus and Intermediate Hyperglycemia: Report of a WHO/IDF Consultation. Geneva: WHO.

32. American Diabetes Association (2008) Diagnosis and classification of diabetes mellitus. Diabetes Care 31, Suppl. 1, S55-S60.

33. Ko GTC (2000) Diagnosing diabetes mellitus in the Asian population. Hong Kong Med J 6, 53-60.

34. Gregg EW, Chen H, Wagenknecht LE et al. (2012) Association of an intensive lifestyle intervention with remission of type 2 diabetes. JAMA 308, 2489-2496.

35. Ramachandran A, Snehalatha C, Shetty AS et al. (2012) Trends in prevalence of diabetes in Asian countries. World J Diabetes 3, 110.

36. Kennedy G \& Burlingame B (2003) Analysis of food composition data on rice from a plant genetic resources perspective. Food Chem 80, 589-596.

37. Singh RB, Woodhead T \& Papademetriou MK (editors) (2003) Strategies to Sustain and Enhance Asia-Pacific Rice Production. Proceedings of the 20th Session of the International Rice Commission, Bangkok, Thailand, 23-26 July 2002. Rome: FAO.

38. Fatema K, Rahman F, Sumi N et al. (2010) Glycemic index of three common varieties of Bangladeshi rice in healthy subjects. Afr J Food Sci $\mathbf{4}, 531-535$.

39. Indrasaria SD, Purwanib EY, Wibowoa P et al. (2010) Glycemic indices of some rice varieties. Indones J Agric 3, 9-16.

40. Pathiraje P, Madhujith W, Chandrasekara A et al. (2010) The effect of rice variety and parboiling on in vivo glycemic response. Trop Agric Res 22, 26-33.

41. Shobana S, Kokila A, Lakshmipriya N et al. (2012) Glycaemic index of three Indian rice varieties. Int J Food Sci Nutr 63, 178-183.

42. Yusof BNM, Talib RA \& Karim NA (2005) Glycaemic index of eight types of commercial rice in Malaysia. Malays J Nutr 11, 151-163. 